Thomas Mayer

\title{
Die Ökonomen im Elfenbeinturm
}

\author{
Eine »österreichische« Antwort auf die Finanz- und Eurokrise
}

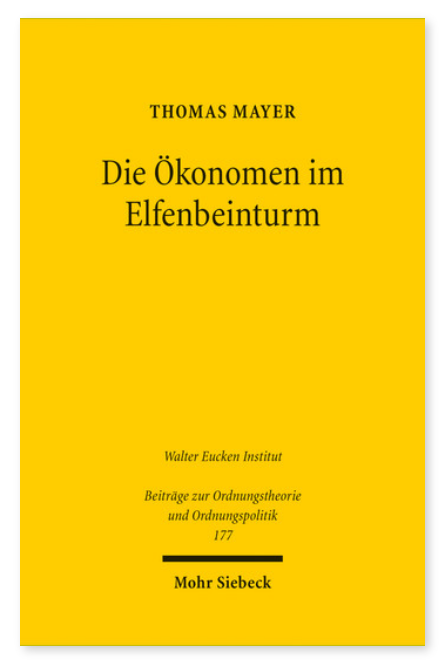

2014. 83 Seiten. BOrd 177

ISBN 978-3-16-152886-6

DOI 10.1628/978-3-16-152886-6

eBook PDF 29,00€

ISBN 978-3-16-152885-9

Broschur $29,00 €$
Verfolgt die Politik gegenwärtig die falschen Rezepte zur Überwindung der Finanzkrise und Stabilisierung des Euro? Thomas Mayer empfiehlt in seiner Hayek-Vorlesung 2012 weniger Konstruktivismus in der Wirtschaftspolitik, einen besseren Ordnungsrahmen für das Spiel der Marktkräfte, die Verbindung von Souveränität und Haftung bei den Staatsfinanzen der EWU-Länder und (in der EWU und anderswo) entpolitisiertes Geld. Er erläutert, wie die Einsichten der österreichischen Schule in die Verbindungen zwischen Realwirtschaft und Finanzsektor in der Vergangenheit von der Politik und dem akademischen Mainstream weitgehend ignoriert wurden, zum Schaden für unser Gemeinwesen. Daraus scheint man auch heute nichts gelernt zu haben. Der Trend geht zu noch mehr Konstruktivismus, mehr Staat, der Vergemeinschaftung der finanziellen Haftung in der EWU und zur Politisierung des Geldes.

Thomas Mayer Geboren 1954; 1982 Promotion; 1983-90 in verschiedenen Funktionen beim Internationalen Währungsfond; 2010-12 Chefvolkswirt der Deutsche Bank Gruppe und Leiter von Deutsche Bank Research; seit 2012 Senior Fellow am Center for Financial Studies der Goethe-Universität Frankfurt und Berater der Geschäftsleitung der Deutsche Bank Gruppe.

Jetzt bestellen:

https://mohrsiebeck.com/buch/die-oekonomen-im-elfenbeinturm-9783161528866?no_cache=1

order@mohrsiebeck.com

Telefon: +49 (0)7071-923-17

Telefax: +49(0)7071-51104 